\title{
The Owl-Eyed, Herculean Cancroid- Hodgkin's Lymphoma
}

\author{
Anubha B* \\ Histopathology and Cytopathology consultant, India
}

*Corresponding author: Anubha Bajaj, Histopathology and Cytopathology consultant, New Delhi, India, Tel: 00911125117399; Email: anubha.bajaj@gmail.com

\section{Mini Review \\ Volume 3 Issue 2}

Received Date: June 07, 2018

Published Date: July 03, 2018

DOI: $10.23880 /$ cclsj-16000125

\section{Abstract}

Initially scripted by Dr Thomas Hodgkin (1798-1866) in 1832, Hodgkin's Lymphoma is a neoplasm, essentially disseminated in a predominantly non-malignant cell population the lymphoma comprises chiefly of $\mathrm{T}$ lymphocytes. The classic Hodgkin's lymphoma (c HL) and the subtype lymphocyte predominance (NLPHD) commences with a B cell clone. The age predominance, surmises two definitive developments: i) A minimally infective agent contaminates the young adults and ii) A synergistic conformity of lymphomas that may explain the pathogenesis of adult Hodgkin's lymphoma. The Epstein Barr Virus (EBV) may be implicated in 30\%-50\% of the immune competent Hodgkin's lymphomas. Array based comparative genomic hybridization (a CGH) may be applied to analyze the genes applicable in the pathogenesis of c HL. The Ann Arbor classification delineates the dominant prognostic categories as the LIMITED (EARLY STAGE) and ADVANCED DISEASE. The Early Stage includes the stage I and II while stage III and IV are encompassed in the Advanced Disease. Stage II along with the systemic symptoms (II B) may be incorporated in the subclass of UNFAVOURABLE Early Stage Disease. The mortality of Hodgkin's Lymphoma has diminished considerably with the current 5 year survival rate at $81 \%$. Where no therapy has been instituted, the survival extends to $1-2$ years with $<5 \%$ of patients existing at 5 years.

Keywords: Herculean Cancroid; Hodgkin's Lymphoma

Abbreviations: HL: Hodgkin's Lymphoma; NLPHD: Nodular Lymphocyte Predominance; EBV: Epstein Barr Virus; CGH: Comparative Genomic Hybridization; LMP: Latent Membrane Protein; HIV: Human Immune Deficiency; RS: Reed Sternberg; DNA: Deoxy Ribonucleic Acid; EORTC: European Organization For Research and Treatment of Cancer; GHSG: German Hodgkin's Lymphoma Study Group; PCR: Polymerase Chain Reaction; ASCT: Autologous Stem Cell Transplantation.

\section{Introduction}

Initially scripted by Dr Thomas Hodgkin (1798-1866) in 1832, Hodgkin's Lymphoma is an infrequent yet treatable adult carcinoma. The malignant elements of the neoplasm are disseminated in a predominantly nonmalignant cell population, chiefly comprised of $\mathrm{T}$ lymphocytes [1,2]. The classic Hodgkin's lymphoma (c $\mathrm{HL}$ ) and the subtype lymphocyte predominance (NLPHD) commences with a B 


\section{Cell \& Cellular Life Sciences Journal}

cell clone, thus the phrase "Hodgkin's Lymphoma" (HL) is implicated rather than "Hodgkin's disease" [1,2]. Regardless, the pathogenesis of the particular lymphoma remains obscure.

\section{Clinical Preponderance}

Hodgkin's lymphoma is a rare disorder. An early stage disease is frequently encountered. The global percentage of Hodgkin's lymphoma and the nodular sclerosis variant in the developing world is minimal, except a higher frequency with adolescents [1]. A "bimodal curve" is predicted with Hodgkin's Lymphoma. 3The bilateral spikes of age predominance, surmises that the disorder may be a culmination of two definitive developments: i) A minimally infective agent contaminates the young adults and ii) A synergistic conformity of lymphomas may explain the pathogenesis of adult Hodgkin's lymphoma $[1,2]$. The Epstein Barr Virus (EBV) genome may be implicated in $30 \%-50 \%$ of the immune competent Hodgkin's lymphomas [1,2]. The Latent Membrane Protein (LMP 1\& 2), EBER (Epstein Barr encoded RNA's) and EBNA (Epstein Barr Nuclear Antigen) may be elucidated in certain tumour estimations [1-3]. Coexistent infectious mononucleosis enhances a probable EBV correlated Hodgkin's lymphoma [1,2]. Instances elaborating HLA $-\mathrm{A}^{*} 01$ exemplify a contingent lymphoma. Nevertheless, EBV negative Hodgkin' Lymphoma may emerge from a hitherto obscure infectious agent. Individuals exposed to blood or blood products, I/V drug abusers and haemophiliacs nonreactive to Human Immune Deficiency (HIV) virus may be susceptible to Hodgkin's Lymphoma [4,5]. Latent HIV contamination amplifies the probability and categories of Hodgkin's Lymphoma.

\section{Morphology/ Histology}

The amended 2008/2016 WHO classification delineates the histological subdivisions of Hodgkin's Lymphoma as "NODULAR LYMPHOCYTE PREDOMINANCE (NLPHD)" at an estimated 5\% and the "CLASSIC" Hodgkin's Lymphoma(c HL) which expounds the remaining projection [5-7]. The subtypes of Classic Hodgkin's Lymphoma are: Nodular Sclerosis, Mixed Cellularity, Lymphocyte Depleted and Lymphocyte Rich $[5,6]$.

\section{Nodular Lymphocyte Predominance (NLPHD)}

The lymph node architecture is generally obliterated and lacks the remnants of the reactive germinal centres. The lymphoma evolves in a nodular fashion and may or may not depict diffuse areas, although, a classic diffuse arrangement is infrequent. The nodular zones are predominantly comprised of $B$ cells abutting a progressive transformation of the germinal centres which may be highlighted by CD20 or CD21 (a follicular dendritic cell marker) reaction $[8,9]$. The malignant cells are enormous with a typical vesicular, irregular, polylobed nucleus and miniature nucleoli. These cells are designated as "L \& H (Lymphocytic and Histioctyic)" or "POPCORN" cells, which emerge in distinct proportions, are disassociated and neither preponderant nor compact $[1,2]$. The non-malignant cellular constituent in NLPHD is composed of small lymphocytes and a proportion of histiocytes, which with focal distribution, may elucidate as non-necrotising granulomas [1]. Abundant epitheloid histiocytes may inhibit the distinction from a $\mathrm{T}$ cell rich large B cell lymphoma and adjunct investigations may be required [10,11]. Plasma cells, eosinophils and neutrophils are infrequent. Adult males are frequently implicated, though the age of disease evolution may be indeterminate [2]. The condition is initially localized and stage IV disease with bone marrow incrimination is sporadic. The mediastinum is uninvolved while the cervical or inguinal peripheral lymph nodes may be frequently implicated [1,2]. Deep seated lymphadenopathies may evolve.

\section{Nodular Sclerosis}

A frequent c HL at an estimated 75\%-80\% diagnosis. Nodules of disparate magnitude are depicted, encompassed by densely fibrotic collagen. The fibrous bands delineate a characteristic green birefringence in polarized light, an element which discriminates the Nodular Sclerosis from the Lymphocyte Depletion. Sporadic foci of coagulation necrosis may be elicited $[1,2]$. The typical feature of classic Hodgkin's Lymphoma is the mammoth bi or multi-nucleated REED STERNBERG (RS) cell with conspicuous nucleoli $[12,13]$.

The prototypical RS cell of classic Hodgkin's Lymphoma (except NLPHL) is a gigantic cell $(>20-50 \mu \mathrm{m}$ in diameter) with ample weakly acidophilic or amphophilic, homogenous or granular cytoplasm. The singular nucleus is bi-lobed or multi-lobed, besides definite bi-nucleation or multi-nucleation may ensue. The nuclear membrane is distinct. The vesicular nucleus expounds dispersed and coarse chromatin clumps. A massive, rounded or variable, highly acidophilic central nucleolus is visible, enveloped by a clear halo. The classic RS cells elucidates two abutting nuclear lobes (mirror image) thus formulating the "owl-eyed" representation [10]. Multiple lobes manifest as an "egg basket". Mononuclear varieties which lack the nuclear lobes are designated "HODGKIN'S CELLS". The diagnostic requisite 


\section{Cell \& Cellular Life Sciences Journal}

is a cell with a bi-lobed nucleus and a conspicuous acidophilic nucleolus in one of the nuclear lobes $[12,13]$. A mammoth RS cell with pleomorphic, hyperchromatic nuclei similar to the cells of an anaplastic carcinoma or a pleomorphic sarcoma may also be exemplified. An RS cell distinguished by darkly staining and retracted features and alluded to as the MUMMIFIED or the NECROBIOTIC variant [2]. The RS cells require a distinction from the a) Megakaryocytes, which in the paraffin embedded haematoxylin \& eosin stained sections delineate an intense periodic acid schiff (PAS) positive substance in the cytoplasm and a phenotype reactive for Factor VIII related antigen and CD61. Morphologically identical b) pleomorphic immunoblasts may be detected in Infectious Mononucleosis and concomitant viral infections [6,7]. c) Malignant cells from a variety of epithelial and mesenchymal tumours may simulate RS cells. d) Malignant Non Hodgkin's Lymphomas may be accompanied by cells analogous to the RS cells [12,13]. An atypical lymphoid population on cytology cogitates upon the improbable diagnosis of Hodgkin's Lymphoma. Subsequent biopsy from certified Hodgkin's Lymphoma reduces the necessity of a definitive, classic RS cell or a characteristic immune phenotype. An established polymorphic infiltrate with anomalous mononuclear cells in the absence of classic RS cells in a surgical biopsy of the bone marrow, liver or adjunctive organ may be acknowledged as the confirmation of Hodgkin's Lymphoma. Contemporary corroboration is the majority or complete instances of Hodgkin's Lymphoma indicate B cell neoplasm (functional B cells for NLPHL and crippled $B$ cells for c HL) [10]. Mono nuclear derivatives of RS cells comprise of "LACUNAR CELLS" and "HODGKIN's CELLS". The RS cells are discernible, though inconspicuous, with the Nodular Sclerosis subtype. Classic Hodgkin's Lymphoma may be determined with the typical RS cells amidst the pertinent cellular backdrop of small lymphocytes, plasma cells, esoinophils, neutrophils and histocytes [2]. Adolescents or young adults and a female preponderance are the dictum with Nodular Sclerosis. Nodular Sclerosis c HL frequently localizes in the upper thorax or mediastinum with a perseverance in the lymph nodes and abutting organs [1,2] (Table 1 ).

\begin{tabular}{|c|c|c|}
\hline Feature & Immunoblast & Reed Sternberg Cell \\
\hline \multicolumn{2}{|c|}{ Nucleolus } \\
\hline Staining pattern & Basophilic & Acidophilic \\
\hline Contours & Irregular & Regular with clear halo (inclusion like) \\
\hline Position & Adjacent to nuclear membrane & More centrally located \\
\hline \multicolumn{3}{|c|}{ Cytoplasm } \\
\hline Staining pattern & Usually Amphophilic & Usually acidophilic \\
\hline Pyroninophilia & Invariably strong & Variable \\
\hline Paranuclear Hof & Prominent & Inconspicuous \\
\hline Encompassing Cells & Mononuclear immunoblasts and plasmacytoid cells & Lymphocytes and Histiocytes \\
\hline
\end{tabular}

Table 1: Analogy of Pleomorphic Immunoblast and Reed Sternberg Cell [2].
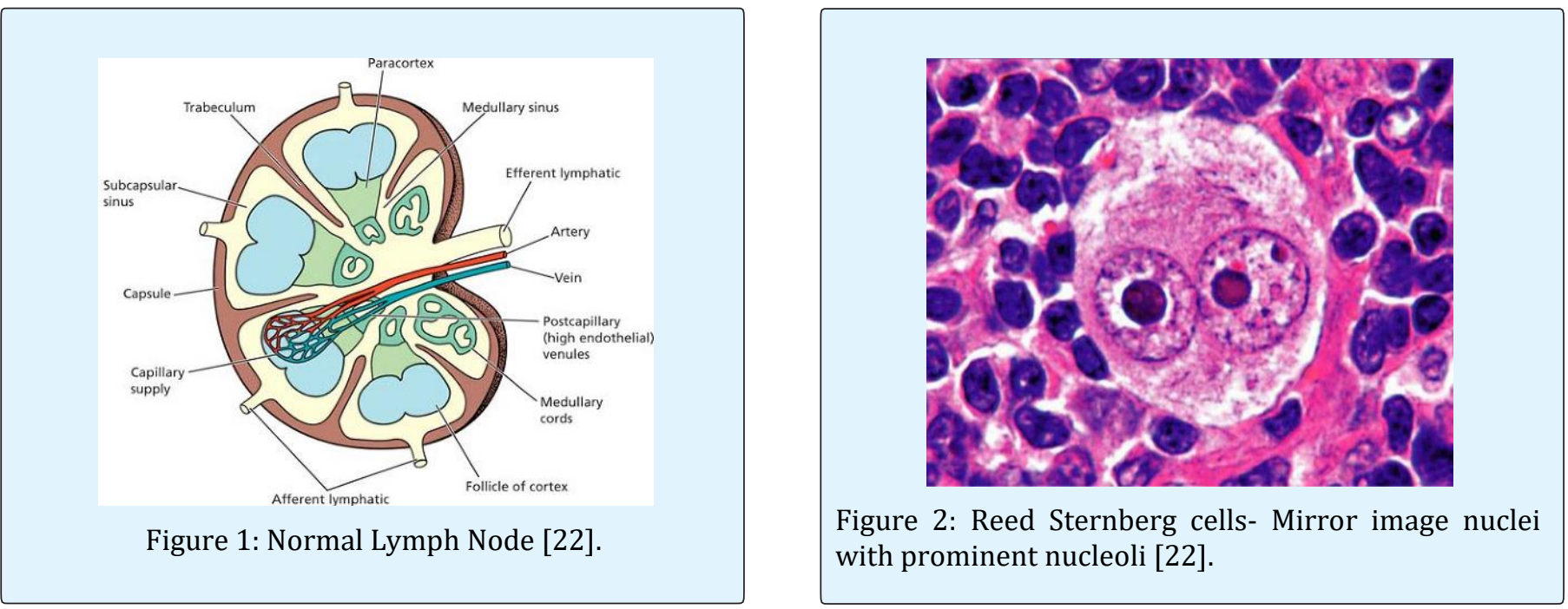


\section{Cell \& Cellular Life Sciences Journal}
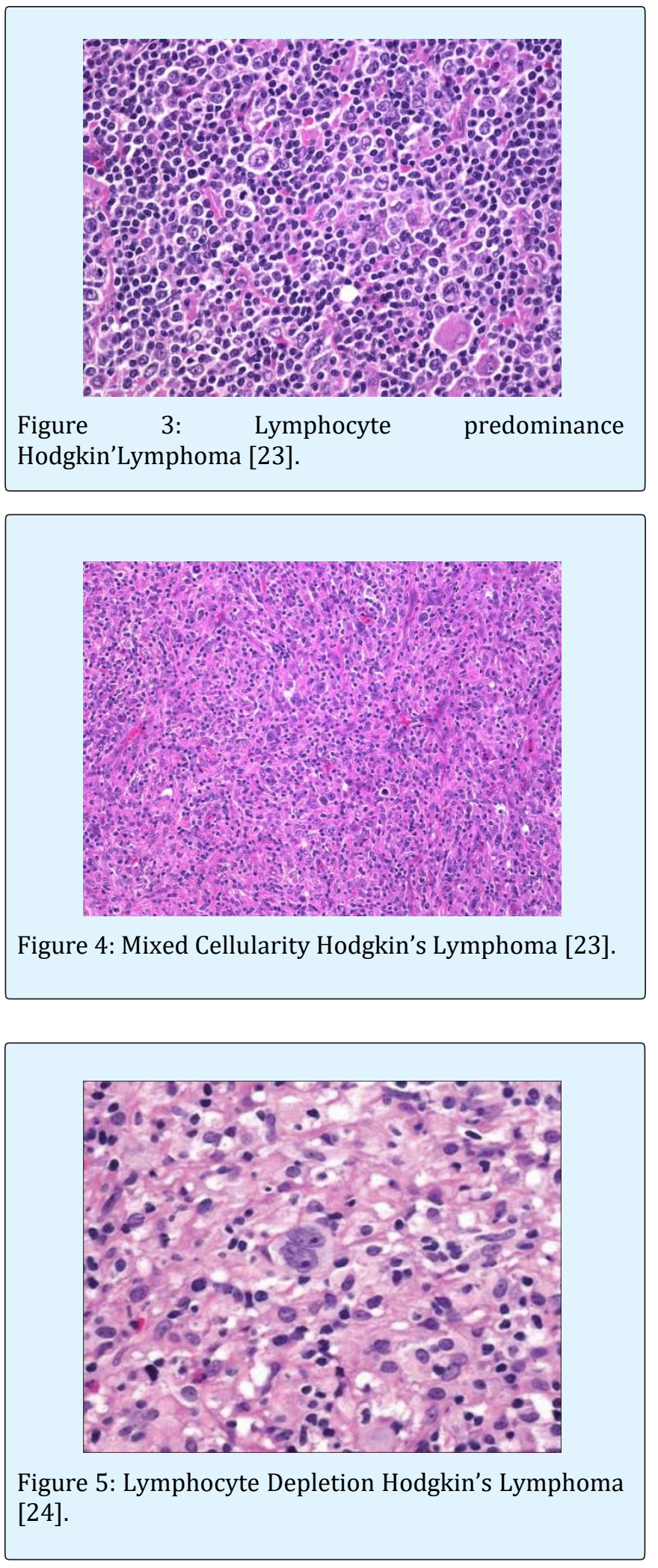
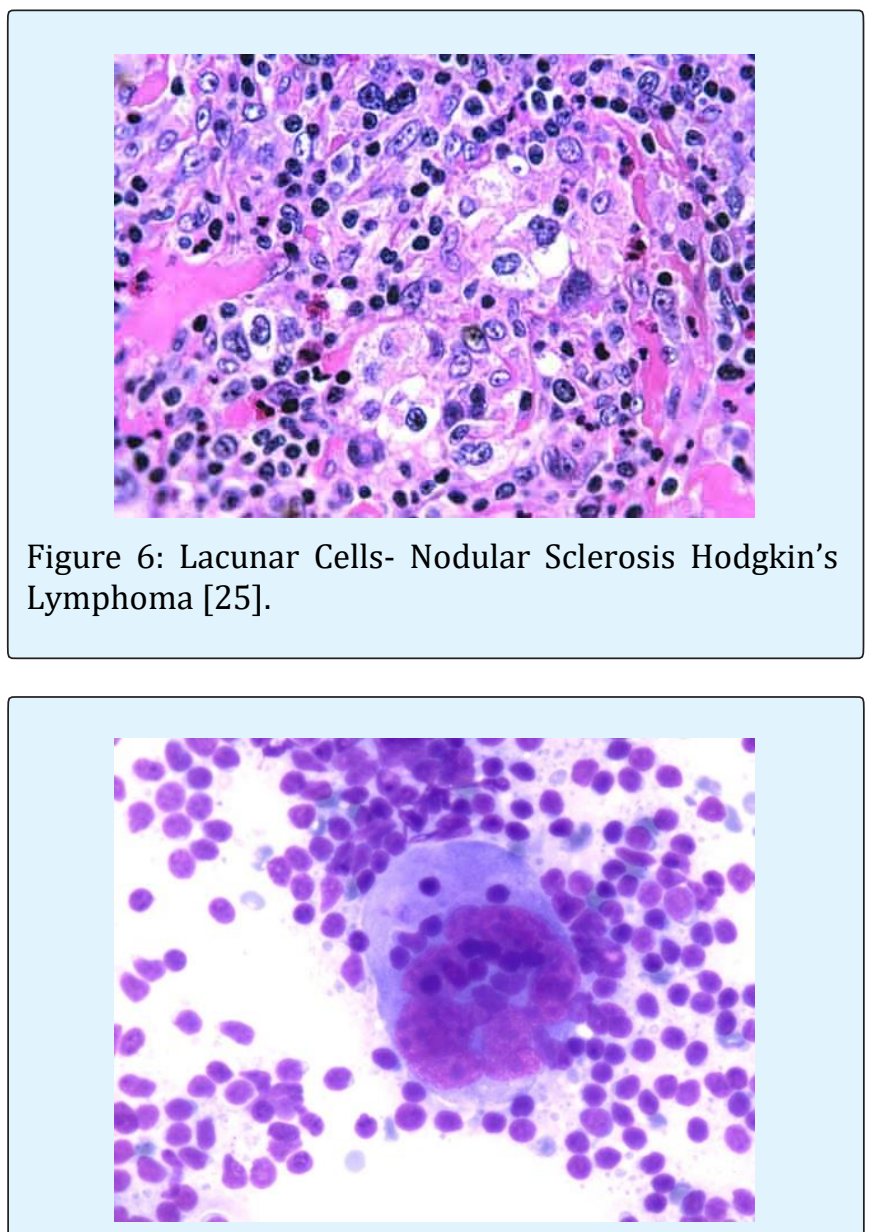

Figure 7: Reed Sternberg cell- aspiration cytology [26].

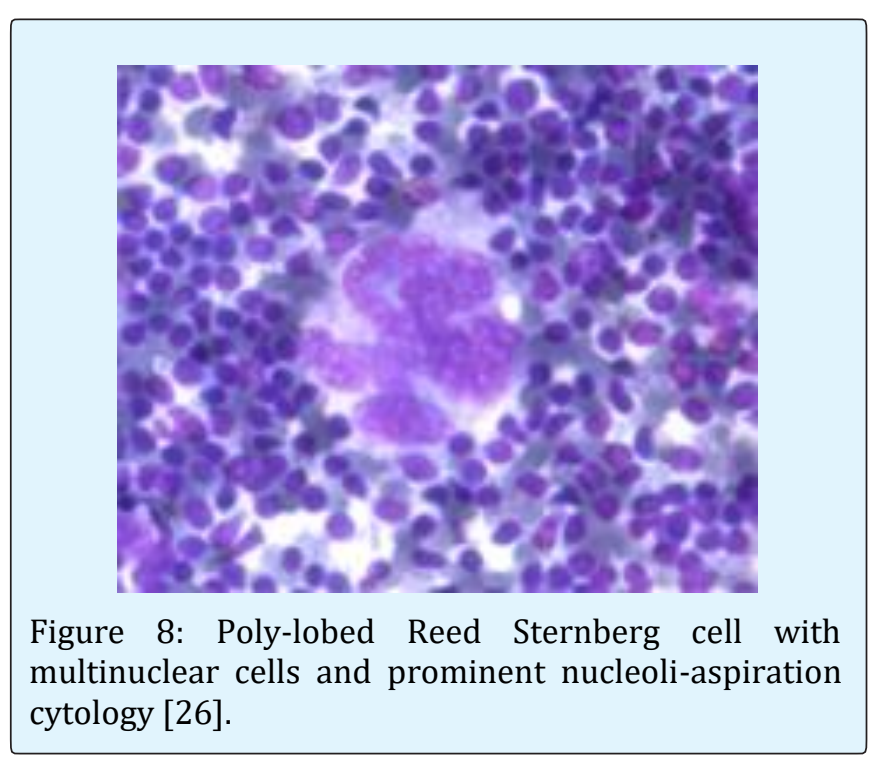




\section{Cell \& Cellular Life Sciences Journal}
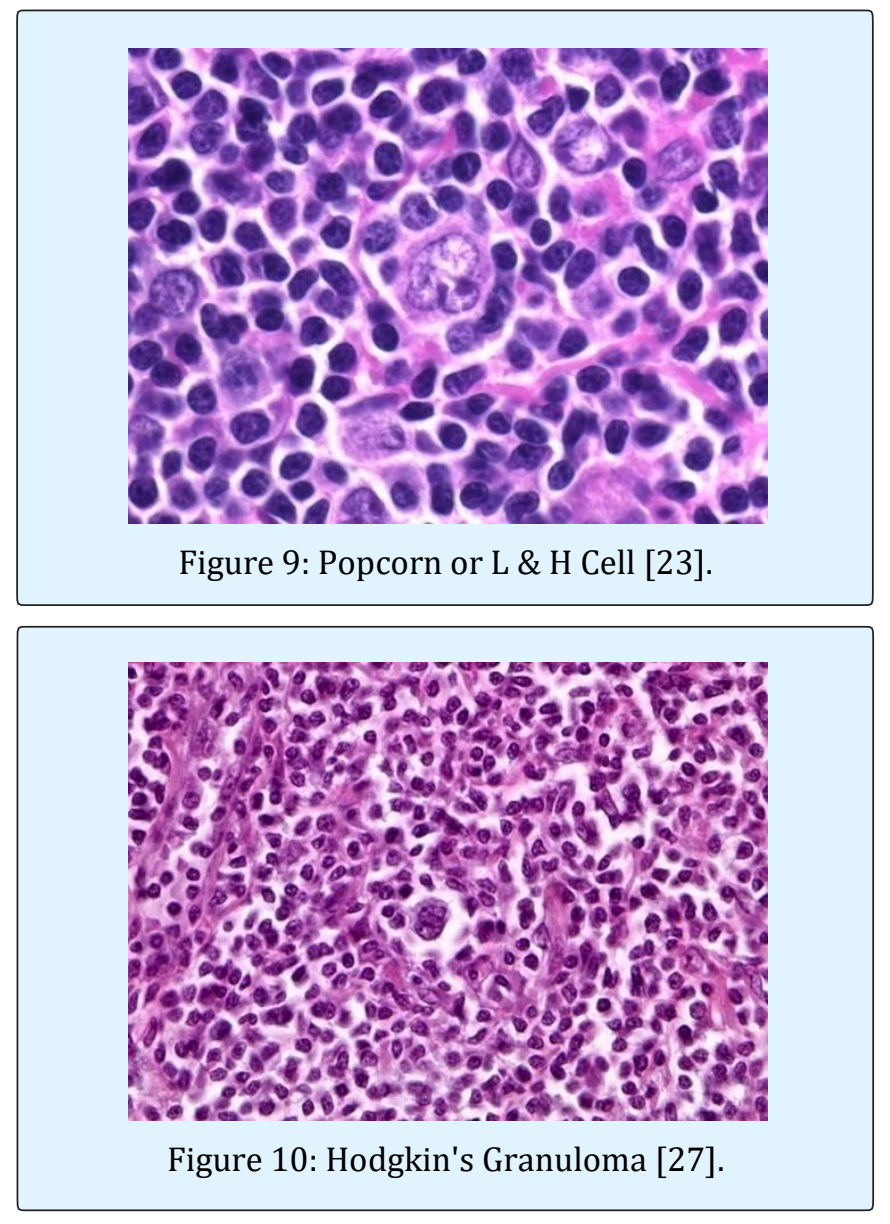

\section{Mixed Cellularity}

The progression of $\mathrm{c}$ HL to the mixed cellularity subtype from the Nodular Sclerosis/ Lymphocyte Predominance, is constituted of a diffuse or slightly nodular cellular infiltrate with multitudinous RS cells, lack of coarse, structured sclerosis with delicate interstitial fibrosis. Adult males are preponderantly affected, in contrast to the females. The bone marrow, lymph nodes, spleen and liver may be implicated $[1,2,8]$.

\section{Lymphocyte Depletion}

Extensive disintegration of the lymph node framework with a predominant, diffuse and compact fibrosis (lacking the bi-refringent collagen) is visualized. Necrosis may ensue. The chief cellular composition is that of RS cells with a minimal reactive, non-malignant environment. The implicated lymph node may manifest with a "SARCOMATOID" character. Cohesive aggregates of RS cells formulate the specific "RETICULAR VARIANT" or" HODGKIN'S SARCOMA" [1,2]. The discrimination of the reticular variant from the anaplastic large cell lymphomas may be challenging. c HL lacks the ALK protein and the genetic rearrangements which organize the $T$ cell receptors [14]. Lymphocyte Depletion, an exceptional subtype, may be elucidated in the geriatric population and in the developing world [1]. Frequently depicted is abdominal lymph-adenopathy or extra-nodal metastasis in spleen, liver, bone marrow. The lymphoma is likely to accelerate and the prognosis is worse than with other subcategories.

\section{Lymphocyte Rich}

An estimated $6 \%$ of the c HL transform to the Lymphocyte Rich category [2]. A diffuse or a focal, intermittently inter-follicular manifestation besides a reactive cellular milieu composed of small lymphocytes, scant neutrophils, eosinophils and plasma cells is encountered. RS cells are uncommon, instead a few LACUNAR CELLS are detected which demonstrate of the immune-phenotypic /molecular features of c HL [2]. Germinal centres and focal fibrosis is exhibited in the nodules. A contemporary subtype of lymphocyte rich c HL may clinically delineate a typical description of delayed presentation (elderly individuals $>50$ years), diminished cellular infiltration, recent appearance with subdiaphragmatic tumour deposits [1,2]. However mediastinal occurrence or extra-nodal sites, systemic symptoms and bulky tumour protuberances are infrequent (Table 2).

\begin{tabular}{|c|c|c|c|c|}
\hline $\begin{array}{c}\text { Jackson and } \\
\text { Parker(1947) }\end{array}$ & $\begin{array}{c}\text { Smetana and } \\
\text { Cohen(1956) }\end{array}$ & Lukes (1963) & $\begin{array}{c}\text { Rye's Conference } \\
\text { (1966) }\end{array}$ & Real/Who 2001/2008/2016 \\
\hline Paragranuloma & Paragranuloma & $\begin{array}{c}\text { Lymphocytic and Histiocytic } \\
\text { (nodular),Lymphocytic and } \\
\text { Histiocytic (diffuse) }\end{array}$ & $\begin{array}{c}\text { Lymphocyte } \\
\text { Predominant }\end{array}$ & $\begin{array}{c}\text { Nodular lymphocyte predominant } \\
\text { Classic, lymphocyte rich subtype }\end{array}$ \\
\hline Granuloma & Granuloma, & $\begin{array}{c}\text { Mixed Cellularity, Nodular } \\
\text { Sclerosis }\end{array}$ & $\begin{array}{c}\text { Mixed Cellularity, } \\
\text { Nodular Sclerosis }\end{array}$ & $\begin{array}{c}\text { Classic, Mixed Cellularity subtype, } \\
\text { Nodular Sclerosis, subtype }\end{array}$ \\
\cline { 2 - 4 } Nodular Sclerosis & Sarcoma & Diffuse Fibrosis, Reticular & $\begin{array}{c}\text { Lymphocyte } \\
\text { Depletion }\end{array}$ & $\begin{array}{c}\text { Classic, lymphocyte depletion } \\
\text { subtype }\end{array}$ \\
\hline
\end{tabular}

Table 2: Comparison of Different Classification of Hodgkin's Lymphoma [2]. 


\section{Cell \& Cellular Life Sciences Journal}

\section{Distinctive Morphologies}

Classic Hodgkin's Lymphoma may depict aggregates of foamy macrophages, eosinophils or may configure eosinophilic microabcesses, inflammatory cells such as S100 protein positive dendritic reticulum cells, mast cells or monocytoid B cells on histology $[12,15]$. Focal interfollicular cellular interposition may be exhibited with florid reactive hyperplasia and the emergence of INTERFOLLICULAR LYMPHOMA. Follicular Hodgkin's Lymphoma may be restricted to the germinal centres. Castleman like disease and a plasma cell rich infiltrate with atypical germinal centres and RS cells exuding Interleukin 6 (IL6) may be demonstrated. Fibrosis may ensue to the extent that an Inflammatory Fibro-sclerosis may be implicated. Spindle cell proliferation may concur which resembles a Fibro-sarcoma or Malignant Fibrous Histiocytoma or a Follicular dendritic cell tumour $[16,17]$. Non-Caseating Granulomas and Vascular Invasion may be encountered.

\section{Immunophenotype}

Lymphocyte predominance Hodgkin's Lymphoma: L \& $\mathrm{H}$ cells are specifically reactive for $\mathrm{CD} 45+$ and $\mathrm{B}$ cell antigens (CD 19, CD 20, CD 22, CD 79a) positive with CD w $75+$ EMA +/- and CD 15-. BCL 6 is regularly present in the malignant cells. CD 30 is generally lacking, though it may be sporadic or moderate, in contrast to c HL $[1,2]$. Paraffin embedded sections elucidate Immunoglobulin light chain restriction. J chain appears consistently [6]. Transcription factors PAX-5, Oct -2, PU-1 and the co-activator BOB.1 are persistently elucidated [1,2]. Contemporary molecules such as HG A1, AID and Centerin may be depicted by the $\mathrm{L}$ $\& \mathrm{H}$ cells $[1,2]$. The reactive environment of the nodules is dominantly comprised of small lymphocytic B cells and sporadic $\mathrm{T}$ cells which configure rosettes encircling the $\mathrm{L}$ \& $\mathrm{H}$ cells with prominent CD 57+, MUM 1, PD $1+$ miniature aspects. The cellular milieu is replete with CD68+ histiocytes and a predominant network of follicular dendritic cells, especially appreciable amidst the nodules [2].

\section{Classic Hodgkin Lymphoma with NS, MC and LD Subtypes}

Paraffin sections exemplify RS cells which are exhaustively CD30+ (a typical crispy membrane and/or dot like staining motif). PAX 5+ (a moderate nuclear indication) in contrast to peripheral small B lymphocytes and CD 45- cells $[1,2]$. CD15 immune marker is generally positive. CD20 can be discerned in 30\%-40\% of classic Hodgkin's Lymphoma, which exhibits a moderate signal, in contrast to a $\mathrm{T}$ cell rich diffuse large B cell lymphoma [10]. Besides, numerous co-existent RS cells may not react to the specific marker. Adjunctive molecules staining the RS cells are MUM-1 and BLIMP which may be detected in $25 \%$ cases $[1,2]$. $\mathrm{T}$ cell antigens are minimally expressed. Numerous molecules elaborated in the Lymphocyte Predominance subtype are lacking in the c HL particularly the OCT -2 , BOB.1 and CD 45 [1,2]. Though the lymphoma is diagnosed on paraffin embedded material, an immunephenotype is an indispensable procedure (Table 3).

\begin{tabular}{|c|c|c|c|}
\hline Immune Marker & Hodgkin's lymphoma & Primary mediastinal large B cell lymphomaDiffuse Large B cell lymphoma \\
\hline CD 45 & $-/+$ & + & $+/-$ \\
\hline CD 20 & $-/+$ & + & + \\
\hline CD 79a & $-/+$ & + & + \\
\hline PAX 5/BSAP & + & + & + \\
\hline BOB.1 & - & + & + \\
\hline 02-0ct & - & + & + \\
\hline PU-1 & - & + & $-/+$ \\
\hline BCL-2 & $-/+$ & + & $-/+$ \\
\hline CD 30 & + & $+/-$ & \\
\hline HLA-DR & + & + & $-/+$ \\
\hline MAC protein & $-/+$ & $+/-$ & $+/-$ \\
\hline BCL-6 & - & $+/-$ & $-/+$ \\
\hline MUM-1/IRF 4 & + & $+/-$ & - \\
\hline CD 10 & - & $-/+$ & - \\
\hline CD 21 & - & - & - \\
\hline CD 15 & + & - & - \\
\hline CD 68 & - & - & \\
\hline T-cell markers & $-/+$ & - & \\
\hline
\end{tabular}

Table 3: Immunohistichemical Profile [1]. 


\section{Cell \& Cellular Life Sciences Journal}

\section{Genetic and Biologic Attributes}

The putative counterpart of Hodgkin's Lymphoma differentiates by falling into 2 categories (main groups). The cellular constituent of the Germinal Centre cells arrested at the centroblast stage may emerge as Lymphocyte predominance Hodgkin's Lymphoma [18]. The premise is endorsed by the rearrangement of the immunoglobulin genes discovered at the deoxy ribonucleic acid (DNA) or the messenger ribonucleic acid (mRNA) levels. The ongoing mutations in the variable portion of immunoglobulin heavy chains are also implicated. RS cells display somatic hyper-mutation genes in all situations and non -sense mutations or deletions in $25 \%$ instances. The genesis of the RS cells from the preapoptotic germinal centre B cells is surmised due to these characteristics [1]. The Hodgkin's RS cells organizes the tissue disorder by gathering the neighbouring immune cells, such as the non-malignant $\mathrm{T}$ helper lymphocytes, plasma cells, macrophages, mast cells and eosinophilic granulocytes. RS cells are commonly encompassed by a rosette of CD 4+ T cell lymphocytes of the TL1 and TL2 pair. EBV reactive disease elucidates a deviation towards the TL1 type [1]. RS cells regulate their continuation and multiplication through various cytokines and chemokines which may collaborate with the enveloping reactive cellular milieu $[13,16]$. Diverse networks are intrinsically mobilized in the c HL especially the NF-KB, JAK / STAT and anomalous formulation of RTK's EBV reactive Hodgkin's RS cells commence from inherently infected B cells, contaminated with EBV [7]. Hodgkin's lymphoma cell integrates the viral genomes in the pattern of multitudinous, covalently closed episomal DNA (as in Burkitt's lymphoma). Molecular assay discloses the viral genomes to be clonal, thus surmising that they commence from a common proliferating precursor. Reactive EBV can be coordinated with Mixed Celluarity subtype and a non mediastinal location with minimal coordination with age/sex of the patient $[7,8]$. EBV contamination occurs in the tumour cell or may appear in the bystander cells [7]. Patients with EBV + Hodgkin's Lymphoma display a favourable outcome. Elderly patients and EBV reactive disease generally elucidate a worse prognosis [7].

Array based comparative genomic hybridization (a $\mathrm{CGH}$ ) may be applied to analyze the genes applicable in the pathogenesis of c HL. Persistent over-expression of 14 genes and down regulation of 141 genes is encountered in the Hodgkin's Lymphoma cell lines [3]. A CGH divulges chromosomal gains in $2 \mathrm{p}, 7 \mathrm{p}, 9 \mathrm{p} 11 \mathrm{q}$ and $\mathrm{Xq}$ and chromosomal loss in $4 \mathrm{q}$ and 11q [1,2]. Chromosomal growth in $2 p$ and $9 p$ may not correspond to the enhanced formulation of the prospective target genes such as c REL and JAK 2. Down regulation of multi-various genes in the Human Leukocyte Antigen (HLA) zone may not coordinate with the deletion of DNA. Consistently, a CGH displays an impairment of $B$ cell phenotype and a downregulated HLA genetic elucidation in the Hodgkin's Lymphoma cells. The molecular karyotypes of c HL depict non random DNA images and modifications as detected by a CGH $[13,16]$. Various persistent genetic lesions may concur with the disease outcome [1,2]. Gene expression profiling (GEP) exhibits an intense alliance between Classic Hodgkin's Lymphoma and a Primary Mediastinal Large B cell Lymphoma (PMLBCL) [1]. $30 \%$ of the genes elucidated in the PMLBCL may typically be integrated in the c HL, in contrast to other Diffuse Large B Cell Lymphomas (DLBCL). PDL2, which encodes the regulator of $\mathrm{T}$ cell stimulation, is the gene which discerns the PMLBCL from adjuvant DLBCL and is intensely enunciated in the Hodgkin's Lymphoma cells [1]. Thus a molecular association and a mutual continuance network between PMLCBL and c HL may be demonstrated. PMLBCL minimally delineate the diverse elements of the $B$ cell receptor signalling cascade, a characterization which is identical to the RS cells of c HL. The pair depicts an augmentation of interleukin 13 (IL13) receptors and downstream effectors of the interleukin 13 signalling receptors (JAK 2 and STAT 1), TNF family members and TRAF 1 . With the emphasis of TRAF 1 and the connection to $\mathrm{NF}^{\mathrm{k}} \mathrm{B}$, a nuclear translocation of $\mathrm{c}$ REL protein has been exhibited in the instances of PMLBCLs $[1,2]$.

\section{Clinical Exposition}

Hodgkin's Lymphoma predominantly emerges as a superficial, asymptomatic lymph-adenopathy. The painless lymph node enlargement exhibits a rubbery, matted or discrete swelling and is frequently located in the neck and the supra-clavicular region [2]. It may be detected incidentally. Mediastinal expansion may be the frequent initial symptom on periodic chest x-rays. The usual sites of involvement are the cervical, supra clavicular and mediastinal lymph nodes (over $50 \%$ cases). A sub-diaphragmatic appearance is infrequent while the epi-trochlear lymph nodes, waldeyer's ring, testicular and gastrointestinal locations are rare [1,2]. Elderly patients frequently exhibit abdominal lymph node enlargement with fever and night sweats. Bone marrow and hepatic infiltration is infrequent. Spleen is generally implicated in concurrence with hepatic disease and systemic symptoms $[1,2]$. Almost $30 \%$ instances display systemic symptoms which preponderate as fever, night sweats and weight loss and infrequently, pruritus which may not be 


\section{Cell \& Cellular Life Sciences Journal}

considered as a systemic symptom [2]. However generalized pruritus requires investigation, if determined to be secondary to scratch lesions or refractory to steroid therapy [1]. Alcohol induced pain, though uncommon, is characteristic and is provoked by consumption of moderate alcohol and is confined to one of the submerged, implicated anatomic site. Progressive Hodgkin's Lymphoma may exhibit rare symptoms such as the superior vena cava syndrome, acute spinal cord compression, solitary lesion of the central nervous system, waldeyer ring inclusions, testicular masses or intestinal occlusions [10].

\section{Staging and Restaging}

The definitive staging system employed for Hodgkin's Lymphoma is the Ann Arbor staging (1971) essentially adapted at Cotswold in 1988 [1,2]. The staging procedure indicates the total number of lymph nodes, the incriminated locations and the appearance of disease above and below the diaphragm, in concordance with the four stages of the disease. Comprehensive staging performance for Hodgkin's Lymphoma requires a detailed history, the occurrence and the duration of probable systemic symptoms and an accurate physical examination. Detailed haematological and biochemical assay (Erythrocyte Sedimentation Rate, Serum Alkaline Phosphatise, Renal Function Tests/Liver Function Tests) Chest x-rays, Chest and Abdominal computed tomography (CT) scans, complete Skeletal $\mathrm{x}$-rays when necessary and Bone Marrow Biopsy [1,2]. Bone marrow core biopsy is beneficial in contrast to a bone marrow aspiration. Patients included in clinical supra-diaphragmatic stage I and II without B symptoms exhibit a minimal possibility of bone marrow complications. Thus a Bone Marrow Biopsy is especially significant in persons elucidating B symptoms and/or phases of clinical progression and/or infra-diaphragmatic tumour appearance and in patients depicting bone marrow lesions, bone pain, hypercalcemia and/or an enhanced serum alkaline phosphatise $[1,2]$. The futuristic application of 18 FDG-PET/CT remains a controversial issue [14]. The 18FDG- PET and PET/CT is a sophisticated technique than the conventional CT which may be utilized to recognize the nodal and extra-nodal disease detected in primary staging $[14,15]$. The 18 FDG PET or PET/CT is more appropriate than conventional CT for analyzing the extra-nodal disease instead of the nodal intricacies [14]. The false positive rate of 18FDG-PET is denoted to be 2\% [19]. Employment of the technique for the initial staging may be beneficial in correlating the outcomes with the subsequently performed 18 FDG-PET to suitably assess the early and terminal outcome of chemotherapy [14].

\section{Ann Arbor Staging System}

Stage I: Involvement of a single lymph node region or a single lymphoid structure such as spleen, thymus, Waldeyer's ring (I) or a single extranodal organ or site (IE or Ig) $[1,2]$.

Stage II: Involvement of two or more lymph node regions or lymphoid structures on the same side of the diaphragm (II) or localized involvement of an extralymphatic organ or site (II E or IIg).The number of anatomical regions should be indicated by a subscript (e.g. II 3). Mediastinal nodes are a single lymph node region.

Stage III: Involvement of lymph node regions or lymphoid structures on both sides of the diaphragm (III) and localized involvement of an extralymphatic organ or site (IIIE or IIIg) or spleen (IIIs) or both (IIIEs). Moreover stage III is characterized by splenic, hilar, celiac or portal node involvement and can be distinguished from III2 which presents with para-aortic, iliac and /or mesenteric node involvement.

Stage IV: Diffuse of disseminated involvement of one or more extralymphatic organs with or without associated lymph node involvement. Localized involvement of the liver or bone marrow is also considered Stage IV. The organs involved should be identified by a symbol.

\section{Extranodal Disease}

Extranodal categorization in stages I to III includes a single extra-lymphatic involvement by limited direct extension from an adjacent nodal site. Extranodal involvement should be identified by a symbol (M: Marrow, L: Lung, D: Skin, H: Liver, P: Pleura, O: Bone. Systemic Symptoms: Fever $>38^{\circ} \mathrm{C}$ of no evident cause for 3 consecutive days, night sweats, unexplained weight loss $>10 \%$ body weight. Patients should be demarcated on the basis of the presence (B) or not (A) of symptoms. Bulky Disease: Palpable masses and abdominal masses (CT scan or MRI) are defined as "bulky" when its largest diameter is $>10 \mathrm{~cm}$. Mediastinal mass is defined as "bulky" on a postero-anterior chest radiograph, when the maximum width is $\geq 1 / 3^{\text {rd }}$ of the internal transverse diameter of the thorax at the level of the T5/T6 vertebra.

\section{Molecular Analysis of Minimal Residual Disease}

Employment of the tumour cell specific reconstructed immunoglobulin DNA sequences by a single cell Polymerase Chain Reaction(PCR) permits the labelling of RS cells in various tumour specimens especially the peripheral blood or bone marrow. The procedure may 


\section{Cell \& Cellular Life Sciences Journal}

also genetically recognize the identical RS cells in the peripheral blood of the individuals with recurrent Hodgkin's Lymphoma, irrespective of the time elapsed since the clinical remission/ initial appearance $[1,2]$. The fact may be adapted to appraise persisting molecular disease in patients with comprehensive clinical remission besides the detection of adulterated cells in auto-graphs (minimal residual disease) [20]. The procedure may not be advantageous in customary clinical practice.

\section{Post Treatment Estimation}

Restaging requires carrying out of the diagnostic procedures found to be conclusive at initial staging. The evaluation of therapeutic response in Hodgkin's Lymphoma may be compromised by the continuance of the remnant tumour aggregates, chiefly at the mediastinum [1]. Lumps may remain due to fibrosis and may not reveal active disease or a possible recurrence. CT is essential for the interpretation of clinical remission and a distinction from active disease from fibrosis may not be possible [20]. 18FDG -PET is a dependable procedure for the evaluation of continual active disease [14]. The International Working Group (IWG in 1999) appraised the therapeutic response and the consequences in patients of Hodgkin's Lymphoma/Non Hodgkin's Lymphoma based on specific recommendations [1]. The prescriptions examine the probability of ambiguous complete remission [CR (u)]. CR (u) is commonly employed in the evaluation of the mediastinal tumour remnant and describes the normal individuals with absent clinical disease but with perpetual and partial radiological anomalies, incompatible with therapy, localized to a former disease spot [20]. Guidelines require the confirmation of a comprehensive remission 3 months subsequent to cessation of treatment. The extensive employment of 18 FDG-PET as a recent, economical methodology to distinguish fibrotic remnants from continuous, active disease has been motivated by a revaluation of the initial IWG norms [14]. The principles of therapeutic interpretation have been amended (2006) with the incorporation of 18 FDG-PET/CT as a definitive measure in the conclusive restaging procedures [14]. The guidelines may be cited for post treatment assessment [1]. Concurrent commendations are a) 18FDG-PET may not be compulsory at the initial evaluation in order to appraise the eventual outcome. b) The concluding 18 FDG-PET assessment may not be implemented at least prior to 3 weeks of chemotherapy and 8-12 weeks of radiotherapy (RT). c) Singular ocular evaluation is deemed satisfactory. d) Positive uptake is determined as per designated rules (Table 4 )[1].

\begin{tabular}{|c|c|c|}
\hline Complete Remission & $\begin{array}{c}\text { Is the disappearance of all evidence of disease. In both patients with initial positive PET scan and } \\
\text { those without an initial PET a residual mass of any size is permitted as long as it is PET negative. } \\
\text { If the BM is involved before treatment, the infiltrate must have cleared on repeat BM biopsy. }\end{array}$ \\
\hline $\begin{array}{c}\text { Unconfirmed } \\
\text { Complete Remission }\end{array}$ & $\begin{array}{c}\text { Has been eliminated. } \\
\text { Partial Response }\end{array}$ & $\begin{array}{c}\text { Is defined as } \geq 50 \% \text { decrease in the sum of the products of the diameters of up to } 6 \text { largest } \\
\text { Pominant masses. No increase should be observed in the size of the other nodes, spleen or liver. } \\
\text { Marrow assessment, if positive before, is irrelevant for the determination of Partial Response. }\end{array}$ \\
\hline Stable Disease & $\begin{array}{c}\text { Is defined as absence of criterion needed to define both CR/PR and progressive disease. 18FDG- } \\
\text { PET should be positive at prior sites of disease with no new areas of involvement (CT\& PET). }\end{array}$ \\
\hline Progressive Disease & $\begin{array}{c}\text { Includes one of the following situations a) the appearance of a new lesion } \geq 1.5 \text { cm in any axis } \\
\text { (increased FDG uptake) in a previously unaffected site should only be considered positive after } \\
\text { confirmation with other modality and therapeutic decision should not be taken solely on the } \\
\text { basis of 18FDG-PET.b) } \geq 50 \% \text { increase in the sum of the product of the diameter of more than } \\
\text { one node. c) } \geq 50 \% \text { increase in the longest diameter of a previously identified node }>1 \mathrm{~cm} \text { in } \\
\text { short axis. Lesions should be 18FDG-PET positive. }\end{array}$ \\
\hline
\end{tabular}

Table 4: Consensus Imaging Subcommittee of International Harmonization Project in Lymphoma [1]. 


\section{Cell \& Cellular Life Sciences Journal}

\section{Prognosis}

Anatomic commencement of the Hodgkin's Lymphoma is followed by a variable duration of tumour extension and chiefly a contiguous pattern of dissemination within the lymphoid framework and in the abutting lymph nodes $[1,2]$. Subsequently, it may concur in the adjoining viscera and dissipate to the spleen, bone marrow, liver, bone and other organs in a manner identical to a metastatic dissemination of an epithelial carcinoma [2]. Left cervical node is frequently incriminated in conjunction with the retroperitoneal lymph nodes, instead of the right edge. Left cervical and retroperitoneal lymph nodes elucidate a mediastinal lymph-adenopathy in $85 \%$ instances. Thus it may be proposed that Hodgkin's Lymphoma may not be consistent in extension by a contiguous fashion [1]. Splenomegaly may be a distinctive occurrence, a fact which conveys that the spleen may be involved in the initial haematogenous dissemination of the disease. The disease may propagate to the spleen, hilum or retroperitoneal lymph nodes [1,2]. Though the splenic dissemination is frequently by a haematogenous route, it does not comprise of an evident, diffuse and extensive haematogenous disorder, as regional radiotherapy along with Splenectomy may alleviate the symptoms. Hodgkin's Lymphoma may progress with a continual depletion of lymphocytes and an augmentation of the malignant cells, as evaluated on histology [1,2]. Lymphocyte Predominance subtype often emerges as a singular lymph node enlargement [10]. The disorder develops gradually and may elucidate numerous recurrences, which are rarely lethal. Delayed recurrence is frequent, in contrast to the other subcategories of Hodgkin's Lymphoma [10]. The subtype (LP) is frequently accompanied with or may evolve to a large B cell lymphoma or a subsidiary low grade Non Hodgkin's Lymphoma. The disease is protracted, with a prolonged survival, in localized conditions, with or without therapeutic intervention [10]. The mortality of Hodgkin's Lymphoma has diminished considerably in the previous three decades. The current 5 year survival rate is established at $81 \%$. In instances where no therapy has been instituted, the disease accelerates and the survival extends to 1 - 2 years with < $5 \%$ of patients existing at 5 years [1].

\section{Prognostic Factors}

The elucidation of prognostic factors and probability assessment criterion is controversial. Innumerable clinical, histopathology and laboratory specifications are proposed to be of prognostic significance [1,2]. The categories may correspond to the volume of the tumour expressed at the initial detection. The estimation of the tumour burden on the serial whole body CT scan is a competent prognostic indicator [1]. Efficacious therapies necessitate a periodic re- evaluation of the relevant aspects with a reconstruction of the chain of command. The Ann Arbor classification delineates the bilateral and dominant prognostic categories as the Limited (Early Stage) And Advanced Disease [1,2]. The Early Stage includes the stage I and II while stage III and IV are encompassed in the Advanced Disease. Stage II along with the systemic symptoms (II B) may be incorporated in the subclass of UNFAVOURABLE Early Stage Disease (defined with European Organization for Research and Treatment of Cancer- EORTC) or Advanced Disease (German Hodgkin's Lymphoma study group - GHSG). The Early Stage is further prorated into 2 sections of "FAVOURABLE" and "UNFAVOURABLE" disease, depending upon the coexistent clinical or laboratory prognostic parameters. The "unfavourable early stage group "describes a class with a prognostic outcome betwixt favourable early stage and advanced stage. Elements required to distinguish favourable from unfavourable early stage condition are not internationally summarized, though may be identical to EORTC or GHSG classification schemes [1]. The succession of unfavourable prognostic variables( singly or in combination) may be required to switch a patient in stage I or II from a subclass of "favourable" to the "unfavourable" early stage in EORTC and GHSG classification.

\section{Eortc Classification}

Bulky mediastinal mass, age $>50$ years ESR $\geq 50 \mathrm{~mm}$ without B symptoms or $\geq 30$ with B symptoms and $\geq 4$ nodal areas incriminated.

\section{Ghsg Classification}

Bulky mediastinal mass, extra-nodal site, ESR $\geq 50$ $\mathrm{mm}, \geq 3$ nodal areas incriminated. Seven prognostic components (age $\geq 45$ years, male sex, stage IV, serum albumin $<4 \mathrm{mg} / \mathrm{dl}$, haemoglobin $<10.5 \mathrm{mg} / \mathrm{dl}$, WBC $\geq 15000 \mathrm{x} / \mathrm{L}$ and absolute lymphocyte count $<600 \mathrm{x} / \mathrm{L}$ ) have been insinuated in depreciating the 5 year disease survival by $7 \%$ to $8 \%$ in patients with advanced Hodgkin's Lymphoma. These parameters assist with the constitution of the International Prognostic Score (IPS) [1]. The miscellaneous elements analyzed are linked to the 5 year Progression Free Survival (PFS) which was estimated to be $74 \%$ for patients with $0-2$ unfavourable prognostic determinants and $55 \%$ for patients with 3 or more such instruments. The analyses of the prognostic ingredients in patients with recalcitrant or refractory Hodgkin's Lymphoma may be confused by the implementation of the diverse inclusion criterion in various clinical trials. 


\section{Cell \& Cellular Life Sciences Journal}

Nevertheless, tumour recurrence within the principle irradiated region, expeditious relapse (first year), chemorefractory disease along with an inadequate performance capacity, massive mediastinal disease, female sex, B symptoms and extra-nodal disease during a tumour reoccurrence implicates a poor prognosis [1,2]. Superior conclusions may be anticipated when the disease is chemo-sensitive and a successive remission or a somewhat minimal disease consequence is achieved prior to instituting autologous stem cell transplantation (ASCT). A positive 18FDG-PET subsequent to a "Salvage Debulking Chemotherapy" and prior to ASCT may possibly be a component which demonstrates a dismal prognosis in patients with a therapeutic non-performance [14]. Advanced Stage Hodgkin's Lymphoma displays pertinent results following two cycles of adriamycin, bleomycin,vinblastine and dacarbazine( ABVD) chemotherapy and with a18 FDG-PET/CT appraisal, elucidates substantial prognostic outcomes [14]. Identical to an assessment of chemo-sensitivity, 18 FDG-PET/CT may nullify prototypical prognostic elements, inclusive of an IPS score. PET 2 - Advanced Stage patients treated with two cycles of ABVD are anticipated to accomplish a two year PFS record of $>90 \%$ though a two year PFS score $<$ $10 \%$ is predicted in PET $2+$ patients. The prognostic advantage of antecedent 18 FDG-PET/CT may be diminished in patients treated with the current chemotherapeutic regimens such as the escalated bleomycin, etoposide, doxorubicin, cyclophosphamide, vincristine, procarbazine, prednisone (BEACOPP), found to be combative in contrast to the ABVD [1]. Traditional benchmarks for the evaluation and assimilation of 18 FDG-PET are not meant for the interim assessment, rather they should be employed for the computation of the ultimate treatment outcome [14]. The estimation of the equivocal "Minimal Residual Uptake" remains ambiguous. This prognostic component is contemplated to be "Investigational" and is advocated only with clinical trials, till the conclusions become accessible [21] (Tables 5-7).

Expression of Th1 and Th2 cytokines in RS Cells and with primary classic Hodgkin's Lymphoma [3].

\begin{tabular}{|c|c|}
\hline Cytokine & Biologic Activity \\
\hline Th2 -IL4 & Th2 cell differentiation, B cell proliferation/ survival, Ig class switching to IgG4 \& IgE \\
\hline IL 13 & B cell proliferation/survival, Ig class switching to Ig4 \& IgE \\
\hline IL 5 & Eosinophil differentiation, proliferation and activation. \\
\hline IL 6 & $\begin{array}{l}\text { Plasma cell differentiation, acute phase reaction, stimulation of IL-1 and TNF } \underset{\alpha}{\alpha} \\
\text { production }\end{array}$ \\
\hline 1L 9 & T cell and mast cell growth factor \\
\hline 1L 10 & Immunosuppressive effects \\
\hline \multicolumn{2}{|c|}{ Th 1 Cytokines } \\
\hline IL 12 & Th 1 cell differentiation \\
\hline IL2 & T cell growth factor \\
\hline IFN- $-\alpha$ & Macrophage differentiation and activation, NK \& CD 8 T cell activation. \\
\hline
\end{tabular}

Table 5: Expression of cytokines in RS cell lines L-428, KM-H2, HDLM-2, L-1236, L-591, L-540.

Expression of Chemokines in RS cell lines and primary classic Hodgkin's Lymphoma [3].

\begin{tabular}{|c|c|}
\hline Chemokine & Biologic Activity \\
\hline TARC & Th2 cell recruitment \\
\hline MDC & Th2 cell recruitment \\
\hline EOTANIN & Eosinophil, Th2 cell recruitment \\
\hline IP 10, Mig, MIP1 $\alpha$ & Th 1 cell recruitment \\
\hline IL 8 & Neutrophil Recruitment \\
\hline
\end{tabular}

Table 6: RS cell lines L 428, KM-H2, HDLM-2, L-1236, L591, L540.
Expression of TNF Ligand family members in RS cells and primary classic Hodgkin' Lymphoma tissue [21].

\begin{tabular}{|c|c|}
\hline TNF Ligand family member & Biologic Activity \\
\hline TNF $\underset{t}{\alpha}$ & Proinflammatory Cytokine \\
\hline $\mathrm{LT} \alpha \underline{\alpha}$ & Proinflammatory Cytokine \\
\hline CD 40L & $\begin{array}{l}\text { B cell/T cell cooperation in } \\
\text { humoral immune response }\end{array}$ \\
\hline CD30L & Tcell stimulation \\
\hline RANKL & $\begin{array}{l}\text { Tcell/dendritic cell } \\
\text { interaction }\end{array}$ \\
\hline
\end{tabular}

Table 7: RS cell lines L-428, KM-H2, HDLM-2, L-1236, L591, L-540. 


\section{Cell \& Cellular Life Sciences Journal}

Expression of other Cytokines in RS cell lines and primary classic Hodgkin's Lymphoma tissues [3].

\begin{tabular}{|c|c|}
\hline Cytokine & Biologic Activity \\
\hline IL -1 & Pro-inflammatory Cytokine \\
\hline TGF- $\beta$ & $\begin{array}{c}\text { B \& T cell suppression, Fibroblast } \\
\text { proliferation \& collagen synthesis }\end{array}$ \\
\hline IL-3 & $\begin{array}{c}\text { Multi-lineage haematopoietic growth } \\
\text { factor }\end{array}$ \\
\hline IL-7 & Precursor B \& T cell growth factor \\
\hline GM-CSF & $\begin{array}{c}\text { Granulocyte and Monocyte } \\
\text { differentiation factor }\end{array}$ \\
\hline M-CSF & $\begin{array}{c}\text { Monocyte growth \& differentiation } \\
\text { factor }\end{array}$ \\
\hline
\end{tabular}

Table 8: Expression of Cytokines in RS cell lines L-428, KM-H2, HDLM-2, L-1236, L-591, L-540.

\section{References}

1. Gobbi PG, Ferreri AJM, Ponzoni M, Levis A (2013) Hodgkin's Lymphoma Critical Reviews in Oncology/Haematology 85(2): 216-237.

2. Rosai and Ackerman's (2017) Surgical Pathology, Edition $11^{\text {th }}$, Elsevier, pp: 1812.

3. Skinnider BF, Mak TW (2002) The role of cytokines in classic Hodgkin's Lymphoma. BLOOD 99(12): 42834297.

4. Laura h Hodgkin's disease/ Lymphoma.

5. Swerdlow SH, Campo E, Pileri SA, Harris NL, Stein H, et al. (2016) The 2016 revision of world health organization classification of lymphoid neoplasm. BLOOD 127(20): 2375-2390.

6. Kuppers R (2009) Clonotype B cells in classic Hodgkin's Lymphoma Blood 114(18): 3970-3971.

7. Hjalgrim H, Askling J, Rostgaard K, Hamilton-Dutoit S, Path FRC, et al. (2003) Characteristics of Hodgkin's Lymphoma after Infectious Mononucleosis. New England Journal of Medicine 349(14): 1324-1332.

8. Brown JR, Neuberg D, Phillips K, Reynolds H, Silverstein J, et al. (2008) Prevalence of familial malignancy in a prospectively screened cohort of patients with lymphoproliferative disorders. $\mathrm{Br} \mathrm{J}$ Haematol 143(3): 361-368. Erratum in Br J Haematol 145(4): 551.

9. Swerdlow SH, Campo E, Harris NL, Jaffe ES, Pileri SA, et al. (2008) Hepatosplenic T cell Lymphoma: In WHO
Classification Tumours of Haematopoietic and Lymphoid tissues: Lyon IARC pp: 292-293.

10. Schmitz R, Stanelle J, Hansmann ML, Küppers R (2009) Pathogenesis of Classic and Lymphocyte Predominance Hodgkin's Lymphoma. Annu Rev Pathol 4: 151-174.

11. Martelli M, Ferreri A, Di Rocco A, Ansuinelli M, Johnson PWM (2008) Primary Mediastinal Large B Cell Lymphoma "Critical Review in Oncology/ Haematology 68(3): 256-263.

12. Kluvier J, Kok K, Pfeil I, de Jong D, Blokzijl T, et al. (2007) Global correlation of genome and transcriptome changes in classic Hodgkin's Lymphoma. Haematol Oncol 25(1): 21-29.

13. Slovak MI, Bedell V, Ya-Hsuan H, Estrine DB, Nowak NJ, et al. (2011) Molecular Karyotypes of Hodgkin's Lymphoma and Reed -Sternberg cells at disease onset reveals distinct copy number alterations in chemo-sensitive versus refractory Hodgkin's Lymphoma. Clin Cancer Res 17(10): 3443 -3454.

14. Romsee MG, Hindié E, Cuenca $X$, Brice $P$, Decaudin $D$, et al. (2010) 18 FDG-PET/CT bone and bone marrow findings in Hodgkin's Lymphoma may circumvent the use of bone marrow trephine biopsy at diagnosis staging. European Journal of Nuclear Medicine and Molecular Imaging 37(6): 1095 -1105.

15. Cerci JJ, Trindade E, Pracchia LF, Pitella FA, Linardi CCG, et al. (2010) Cost effectiveness of Positron Emission Tomography in patients with Hodgkin's Lymphoma in unconfirmed complete remission or partial remission after first line therapy. Journal of Clinical Oncology 28(8): 1415-1421.

16. Brusamo E, Bacigalupo A, Barosi G, Biti G, Gobbi PG, et al. (2009) classic Hodgkin's Lymphoma in adults guidelines of the Italian Society of Haematology. The Italian Society of Experimental Haematology and the Italian group for Bone Marrow transplantation on initial work up, management and follow-up. Haematologica 94(4): 550-565.

17. Steidl C, Lee T, Shah SP, Farinha P, Han G, et al. (2010) Tumour associated macrophages and survival in classic Hodgkin's Lymphoma. N Engl J Med 362: 875885.

18. Meigner M, Gallamini A, Meignan M, Gallamini A, Haioun C (2009) Report on the first International 


\section{Cell \& Cellular Life Sciences Journal}

Workshop on interim PET scan in lymphoma. Leuk Lymphoma 50(8): 1257-1260.

19. Armitage J (2010) Early stage Hodgkin's Lymphoma. N Engl J Med 363: 653-662.

20. Campbell BA, Voss N, Pickles T, Morris J, Gascoyne $\mathrm{RD}$, et al. (2008) Involved nodal radiation therapy as a component of radiotherapy for limited stage Hodgkin's Lymphoma: a question of field size. J Clin Oncol 26(32): 5170-5174.

21. Connors JM (2011) Hodgkin's Lymphoma- the great teacher. N Engl J Med 365(3): 264-265.
22. Image $1 \& 2$ Courtesy: Pinterest.

23. Image 3, 4 \& 9 Courtesy: Web-pathology.

24. Image 5 Courtesy: Clinical Cancer Investigation Journal.

25. Image 6 Courtesy: pleiad.umdnj.edu.

26. Image $7 \& 8$ Courtesy: Euro-cytology.

27. Image 10 Courtesy: Microscopy u. 